\title{
O arquivo público paranaense: possibilidades para a pesquisa em história da educação no período provincial
}

\author{
Gizele de Souza' \\ Juarez José Tuchinski dos Anjos' \\ Etienne Baldez Louzada Barbosa
}

\section{Resumo}

Este artigo trata a respeito da relação do historiador da educação com os arquivos, das possibilidades de pesquisa e tensões que os acervos produzem na imbricada relação com o pesquisador e das potencialidades do acervo do Departamento de Arquivo Público do Paraná (DEAP-PR). Examina o arquivo quanto aos instrumentos de pesquisa disponíveis - os fundos arquivísticos que contêm documentação referente à instrução pública no Paraná província -, aos conteúdos e tipos de fontes que podem ser encontrados nos respectivos fundos e a relevância desse acervo para a escrita da história da educação no século XIX. 0 objetivo do estudo é analisar os fundos documentais do arquivo, tomando-o como ferramenta fecunda para o trabalho de pesquisa em história da educação, em especial no que se refere às investigações acerca da instrução pública no período provincial. Metodologicamente, o trabalho realizado foi o de mapear no acervo do DEAP-PR as possibilidades de pesquisa sobre instrução nos diversos fundos documentais presentes no arquivo, agregá-los e apontar, diante da natureza e características das fontes empíricas reunidas, o potencial analítico. Para dar conta dos propósitos firmados, o texto dialoga com referências no campo da história e história da educação e apresenta, como resultados, o próprio percurso de organização, a análise dos fundos documentais do arquivo e as possibilidades investigativas para os estudos acerca da instrução pública, em especial, para o período provincial.

\section{Palavras-chave}

Arquivo público paranaense - Instrução pública - Império.

I- Universidade Federal do Paraná, 


\title{
The Paraná public archives: possibilities for a research in the history of education in the provincial period
}

\author{
Gizele de Souza' \\ Juarez José Tuchinski dos Anjos \\ Etienne Baldez Louzada Barbosa'
}

\section{Abstract}

This article deals with the relation of the historian of education to archives, with the possibilities for research, with tensions that the archives introduce in the complex relation with the researcher, and with the potentialities of the Department of Public Archives of Parana (DEAP-PR). It examines the archives as to the research tools available - the archive resources that contain documentation referring to public instruction in the province of Paraná -, as to the contents and types of sources that can be found in the corresponding resources, and as to the relevance of these archives for the writing of the history of education in the 19th century. The objective of this study is to analyze the documental resources of the archive, looking at them as a fertile working tool for the research in the history of education, particularly in what concerns the investigations about public instruction in the provincial period. Methodologically, the work that was carried out was that of mapping out in the DEAP$P R$ archives the possibilities of research in education offered by the various documental resources present in the archives, of bringing them together and of pointing out, based on the nature and characteristics of the empirical sources gathered, their analytic potential. To fulfill these objectives, the text dialogues with references from the field of history and history of education, and presents as results the organizing process itself, the analysis of the documental resources of the archives, and the research possibilities of studies about public instruction, in particular for the provincial period.

\section{Keywords}

Paraná public archives - Public instruction - Empire.

I- Universidade Federal do Paraná, Curitiba, PR, Brazil.

Contacts:gizelesouza@uol.com.br; juarezdosanjos@yahoo.com.br; blb_etienne@hotmail.com 
Criado em 7 de abril de 1855, o arquivo público do Paraná vem acumulando desde então a documentação produzida pela administração pública paranaense (DEAP-PR, 2000). Em função de doações recebidas, o material custodiado atualmente já extrapola o universo administrativo. Contudo, a documentação pública é ainda a sua maior riqueza, sendo um de seus fundos a documentação referente à instrução pública no período provincial - o objeto de análise e problematização do presente artigo.

0 investimento que realizamos na produção de conhecimento sobre a escolarização primária no Paraná imperial, servindo-nos dessa documentação, permite-nos perceber que apesar de ela não ser desconhecida dos historiadores, as possibilidades e limites do referido acervo ainda não foram objeto de uma análise específica no que diz respeito à sua importância para a escrita da história da educação no século XIX, mais especificamente, no período provincial. A experiência no arquivo demonstrou também o quanto a sua lógica difere daquela do historiador. Tendo trilhado esse caminho das pedras, julgamos oportuno partilhar o aprendizado com os demais pares da oficina da história.

A opção por estudar esse arquivo e período, além de refletir as próprias escolhas que temos feito em nossa trajetória de pesquisadores, vai ao encontro do que foi identificado por Xavier (2000) e Catani e Faria Filho (2002): o esforço dos historiadores em cada vez mais produzir conhecimento históricoeducacional sobre os oitocentos, em especial, o período imperial, caracterizado por um projeto de instrução pública cuja organização e implementação, ao ser delegada às províncias pelo Ato Adicional de 1834, gerou múltiplas experiências de escola primária no Brasil. Tal interesse, no entanto, é recente na historiografia da educação. Anteriormente, o século XIX fora visto como um período no qual muito pouco se fez pela escolarização em nosso país. Para Maria Lúcia Hilsdorf (2002), isso se atribui a epistemes como a de Fernando de Azevedo, que até bem pouco tempo marcavam a escrita da história da educação. Segundo ela,

[...] a historiografia desse período vinha sendo feita em uma perspectiva republicana, ou seja, desenvolvendo uma linha de análise que toma como referencial maior o contexto dos embates sócioculturais que envolveram a implantação do novo regime e consagra a imagem do tempo monárquico como um tempo "fraco", por oposição ao tempo republicano "forte" (HILSDORF, 2002, p. 135).

A partir da década de noventa ${ }^{1}$ houve o impulso para que se revelasse o século XIX como o momento em que a escola foi adquirindo papel de destaque no projeto de nação, uma vez que ali se começou a apreender a instrução como uma importante ferramenta de civilização.

Tal produção, sobretudo, somente se concretizou porque os pesquisadores se serviram, sem cerimônia, dos arquivos públicos estaduais e institucionais. Foram essas idas e vindas aos arquivos, amparadas por uma agenda acurada de questionamentos, que possibilitaram a construção de outro olhar sobre a escola primária oitocentista. Nesse sentido, inclusive, nosso estudo soma-se aos de Hilsdorf (1999), Simões e Franco (2004), Bezerra (2006) e Brandão (2007) que, dentre outros, em diferentes momentos, já se dedicaram à reflexão acerca dos arquivos de seus estados e as potencialidades de cada um deles para a história da instrução no período imperial.

Se é ponto pacífico que hoje a historiografıa educacional tem operado não mais exclusivamente com os marcos da história política, mas com recortes diversos efetuados a partir de seus múltiplos objetos, não se deve esquecer que "a educação assume, em cada

1- Destacam-se os grupos de pesquisa em história da educação de várias universidades brasileiras, assim como os investimentos do Grupo de Trabalho de história da educação da Associação Nacional de Pós-Graduação e Pesquisa em Educação (ANPED) e os congressos brasileiros da área. 
momento histórico e em cada formação social, características e funções diferentes." (LOPES, 1981, p. 14). Assim, falar em escola imperial ou escola republicana - naquilo que as une no fenômeno educativo e diferencia no fluxo da experiência social e política com a qual dialogaram, sem abrir mão dos avanços teóricos e metodológicos que já alcançamos - ainda pode contribuir para compreender ou reinterpretar facetas da história da escola em nosso país.

Este artigo está dividido em duas partes. Inicialmente, tecemos algumas considerações acerca da relação do historiador da educação com os seus arquivos a partir de nossa prática historiográfica. Em seguida, procedemos à localização, descrição e problematização dos fundos e instrumentos de pesquisa nos quais estão contidas a documentação referente à instrução pública do Paraná.

\section{O arquivo e o historiador da educação: entre limites, desejos e possibilidades}

Georges Duby escreveu que o ofício do historiador consiste em:

[...] se retirar e mergulhar no silêncio para tentar, mal informado, perdido entre pistas embrulhadas, embaciadas, discordantes, compreender o que se passou há séculos. (DUBY, 1989, p. 111).

Anteriormente, Marc Bloch já havia se referido a essa circunstância por meio de uma metáfora. Comparou a desvantagem do historiador no manuseio de seus documentos em relação à boa testemunha de um fato do presente. Para o autor, o historiador se encontra em uma posição desconfortável, pois

[...] fica como que no fim de uma fila na qual os avisos são transmitidos, desde a frente, de fileira em fileira. Não é um lugar muito bom para se ser informado com segurança (BLOCH, 2001, p. 71).
Podem soar pessimistas essas afirmações de Duby e Bloch, mas valem uma análise mais detida. Comecemos refletindo a respeito das causas dos impasses por eles descritos, no ofício do historiador. Lembremos que o conhecimento que podemos produzir sobre os homens e mulheres do passado se apoia em "lacunas e incertezas”, "fragmentos e ruínas” (GINZBURG, 1991a, p. 232), pois os documentos que buscamos e que em nossa prática interrogamos, transformados em fontes e testemunhas, são sempre escassos. Produzidos em condições e situações bastante diversas e peculiares, não são mais do que fatias de realidade capturadas por seus produtores.

0 problema não para aí. De tudo aquilo que uma sociedade, um grupo ou um indivíduo produz, só uma parte muito ínfıma é legada aos pósteros como imagens que o mesmo grupo ou um de seus membros julgou oportuno de serem guardadas, preservadas e arquivadas. E por ser a partir de tais imagens que o historiador escreve a história é que terá sempre de se contentar em escrever uma história ou histórias no plural, conformando-se ao que aponta Eliane Marta Lopes (LOPES, 2005, p. 119):

A história é aquilo que os historiadores escrevem e não a realidade de um passado inapreensível por sua natureza de já ter passado [...] e os historiadores escolhem ou selecionam as informações que lhes pareçam significativas, rejeitando outras. Nesse trabalho não consegue cercar ou cercear sua subjetividade, não consegue aprisionála em sua pretensão de objetividade. 0 máximo que pode fazer é ser honesto.

Acontece que, antes mesmo das escolhas do historiador, outros já as fizeram por ele: os que ficam à sua frente, na fila a que se referia a metáfora de Marc Bloch.

No tocante à história da educação, Clarice Nunes descreveu bem o ponto em que geralmente nos encontramos: temos certa imagem do passado, legada pelos educadores/ 
historiadores precedentes e buscamos romper ou questioná-la por meio de novas interpretações. Contudo, para avançar precisamos dos arquivos, os quais não guardam apenas sonhos, mas

corporificam na sua existência e na sua organização um poder multifacetado, quer individual (do titular, doador) quer institucional, com o qual medimos nossa força de intervenção. (NUNES, 1990, p. 38)

Clarice Nunes e Marta Carvalho apontam outra característica desse jogo de interesses entre o que a administração pública decide que deve ser preservado ou não e o espaço deixado para atuação do historiador. Segundo elas, a concepção corrente é a:

[...] valorização enfática dos documentos enquanto objetos de caráter comprobatório. [...] 0 valor informativo, que se refere ao uso do documento do ponto de vista científico e cultural, raramente é considerado. (CARVALHO, NUNES, 2005, p. 33).

Em poucas palavras, a desvantagem à qual se referem Bloch e Duby, e que emerge com clareza nas constatações das três historiadoras da educação aqui mencionadas, é aquela que nasce da relação de dependência que o historiador mantém com os seus arquivos. A informação para quem está no fim da fila é quase sempre aquela mediada por eles.

Diante desse quadro um tanto quanto desolador, mas que necessariamente precisa ser enfrentado, é que se inicia a pesquisa histórica. Recordemos como Clarice Nunes a define:

A pesquisa histórica é um trabalho de pensamento que também experimentamos com ação e afeto. Desejar compreender as trajetórias de outros sujeitos [...] é o ato inaugural que nos impele a verificar que o desejo que encontrou nos outros a oportunidade de manifestar-se em obras é, em nós, o móvel do esforço que nos leva a passar horas consultando arquivos ou a permanecer debruçados sobre uma mesa copiando informações, criando e recriando idéias. Este desejo, que encontra em nós a sua origem, movimenta-se na direção dos sujeitos e das coisas habitadas pela história (NUNES, 1990, p. 37).

É justamente no desejo de conhecer e compreender as experiências dos sujeitos contidas nas coisas e espaços habitados pela história que reside o trunfo do historiador para enfrentar as desvantagens sobre as quais refletimos linhas atrás. Esse desejo, enquanto móvel de esforço, aponta que a partir daquilo que limita e ao mesmo tempo seduz - o arquivo, com sua lógica e suas regras -, é que se podem abrir clareiras para o enfrentamento dos problemas que estão no cerne da relação do historiador com os arquivos. Enumeramos, em forma de quatro pontos, possibilidades desse enfrentamento.

1) Um arquivo, em função dos documentos que retém ou contém, testemunha relações de poder e interesses vividas pelos sujeitos e instituições que os produziram, mas também por aqueles que os selecionaram e os preservaram. Assim, no espaço entre aquilo que foi preservado e o que foi descartado, cabem questionamentos da parte do pesquisador. Em relação ao que foi preservado em um arquivo oficial, como é o caso do DEAP-PR, com uma série considerável de documentos sobre a instrução pública, evidencia-se que já em determinada época, não obstante os limites desse ramo do governo, a escola ocupava um lugar e uma importância no projeto de nação que se queria construir e do qual o próprio arquivo é parte integrante.

Se o lugar que a escola ocupa não era o mesmo de hoje, nem por isso era menor. No tocante ao muito produzido pela escola e que não encontrou espaço no arquivo, tem-se uma lacuna que pode sinalizar aspectos do fenômeno educativo que não estavam no horizonte dos interesses primeiros dos envolvidos com a escolarização em determinada época histórica. Isso se mostra ainda mais instigante quando, 
em certo momento, começam a surgir esses documentos que anteriormente eram descartados.

A série documental em um arquivo, com suas falhas e lacunas, pode sinalizar as tão procuradas mudanças no movimento da história. Por essa razão, não encontrar um documento para determinada época e localizálo em profusão em outro período, constitui-se pista e ponto de partida para muitas indagações. Se o historiador faz flecha com qualquer madeira (JULIA, 2001), também o arquivo se torna boa madeira, mesmo quando, na ausência de determinados documentos em seu acervo, ele aparentemente se cala.

2) A prática da pesquisa no arquivo se faz não apenas no recurso ao quantitativo - nas séries documentais que permitem acompanhar determinadas questões ou permanências e mudanças na história da escola em um período de tempo - mas, também, no mote qualitativo, por meio do diálogo com o singular. Tal situação ocorre quando, em meio a séries e lacunas, encontram-se documentos únicos e de difícil encaixe nas categorizações preestabelecidas tanto pelo arquivista como pelo historiador.

Pode haver relatórios de professores questionando decisões de seus superiores, propostas de adaptação de regulamentos de instrução na contramão dos desejos dos presidentes da província, críticas a determinadas práticas escolares ou abaixo assinados de grupos geralmente vistos como excluídos da escolarização, como os pobres, dentre outros. No entanto,

todo o documento, inclusive o mais anômalo, pode ser inserido numa série. Não só isso: pode servir se analisado adequadamente, a lançar luz sobre uma série documental mais ampla. (GINZBURG, 2006a, p. 263)

Assim sendo, o documento singular só ganha e lança luz se restituído por meio dos questionamentos do historiador a um duplo tempo histórico: o de sua produção e o do seu arquivamento. No tempo de sua produção, revela pontos de vista ou práticas diferenciadas daquelas tidas até então por hegemônicas no comportamento dos seus contemporâneos. Mesmo nesse caso, vale lembrar que ninguém está à frente do seu tempo (BLOCH, 2001) ou fora da jaula de sua cultura (GINZBURG, 2006b), pois todos assumem diferentes posicionamentos diante das questões de sua época, revelando tensões ou contradições de determinadas práticas culturais ou sociais com as quais dialoga.

Em relação ao tempo do arquivamento, a custódia do que não se encaixa revela que em função do estranhamento que causou, da originalidade que nele se viu, mereceu ser guardado, armazenado, misturado ao conjunto no qual sempre se destacou. Esse destaque, por sua vez, aponta para outras fatias da realidade do fundo no qual se diferencia. Quando isso ocorre, o arquivo deixa aberta "uma brecha no tecido dos dias, a visão retraída de um fato inesperado" (FARGE, 2009, p. 14) a ser preenchida pelo trabalho do historiador.

3) Arquivos não guardam pessoas, mas revelam pessoas flagradas em suas relações sociais. É tão somente por essa razão que eles são matéria-prima para o conhecimento histórico. Se neles, no mais das vezes, encontramos documentos, devemos tentar, com certa dose de imaginação histórica ou habilidade imaginativa (DAVIS, 2000, p. 108), pensar nas atitudes que seus autores precisaram assumir no momento em que os fabricaram e nas relações que no ato de sua produção mantinham entre si.

No que diz respeito ao primeiro aspecto, os arquivos estão repletos de ações, gestos e atitudes, sendo que cada uma delas é sempre um prática cultural e social. Cultural na medida em que, não obstante a polissemia e fluidez do conceito, a cultura pode ser entendida - no bojo da antropologia de Clifford Geertz - como aquilo que as pessoas fazem, ou seja, as teias de significados e sua análise (GEERTZ, 2008, p. 4). Social porque pressupõe que tais práticas são exercidas sempre em relação a alguém e 
socialmente significadas, o que faz com que o arquivo passe a revelar pessoas quando se decide perseguir. Rompem-se, assim, as séries do arquivista e as séries da organização habitual do trabalho do historiador, o fio do nome,

[...] o fio de Ariadne que guia o investigador no labirinto documental [...] que distingue um indivíduo do outro em todas as sociedades conhecidas: o nome (GINZBURG, 1991b, p. 174).

A perseguição nos arquivos pelos nomes dos envolvidos com a escola em determinadas situações e a partir de diferentes lugares sociais nos quais se revezam - pais, professores, inspetores paroquiais, inspetores de distrito, inspetores gerais, deputados provinciais, presidentes da província - transformam os vestígios dessas presenças em:

[...] documentos históricos no sentido pleno da expressão: além de revelarem relações entre dois ou mais sujeitos, tem também por isso um sentido cultural, na medida em que atestam um costume ou uma tipicidade. (GRENDI, 2009, p. 24).

Por trás dos documentos, na articulação dos nomes e das práticas produzidas por seus portadores, podem-se localizar os diferentes níveis de relação e de apropriação de práticas culturais realizados pelos sujeitos que agiram e construíram o que hoje o historiador compreende como a escola pública de certo período histórico, em particular o período imperial.

0 enfrentamento do arquivo nos termos da busca por essas pessoas e suas relações ajuda, parafraseando Nunes (2009), a trazer para o primeiro plano a responsabilidade das ações humanas e de suas consequências no delineamento de determinados fenômenos históricos.

4) Arquivos não fornecem provas do que foi o passado. São laboratórios de possibilidades históricas. Quanto a esse aspecto, ressaltamos que talvez a maior ilusão em torno do arquivo (e não tão ingênua como muitos podem supor) seja a de que, ao vasculhá-lo e esmiuçá-lo, de ponta a ponta - sempre dentro dos limites daquilo que outros já escolheram anteriormente à operação do historiador -, possam emergir provas da existência de um outro passado, diferente daquele que conhecemos e que nos foi transmitido no acúmulo das cadeias das gerações (BLOCH, 2001).

Afundar-se no arquivo, com semelhante intenção, decididamente, não é a coisa mais sábia a fazer. Para contornar a tentação, Duby recorda-nos a indicação recebida de Charles Edmund Perrin, seu orientador de tese. Vale retomá-la:

[...] agarrar um corpo coerente de documentos [...] experimentar o terreno, traçar as primeiras pistas, ter cuidado para não se enterrar ou perder, tendo para isso os olhos bem abertos aos progressos de conjunto da investigação histórica, ler muito, afınar os instrumentos críticos e deixar amadurecer assim, lentamente, uma investigação. (DUBY, 1989, p. 126)

A prudência de Perrin, transmitida a nós por Duby, não pode ser esquecida quando se está diante de um vasto corpus documental, como é o caso da maioria dos arquivos e, de modo particular, do DEAP-PR, cuja documentação sobre a instrução pública do século XIX - com exceção da que diz respeito às cidades de Paranaguá, Curitiba, Lapa, Rio Negro, Palmeira e Antonina - está quase toda por ser explorada.

Mais vale, talvez, para o historiador, debruçar-se sobre um ou outro aspecto/tema a profissão docente, a organização da inspeção pública, o envolvimento das municipalidades, os investimentos com a instrução, os métodos de ensino, a educação da criança - para sentir o terreno e traçar pistas. Essa necessária humildade de ofício impõe de antemão que jamais será possível esgotar as potencialidades de um arquivo e que necessariamente a produção do conhecimento histórico a partir dele terá de ser coletiva; mais solidária que 
solitária, em redes "de trocas de conhecimentos, buscando fazer dialogar pesquisadores", como propuseram Simões e Franco (2004) no seu estudo sobre o arquivo público capixaba.

Mas então, de que vale o esforço de horas infindáveis que passamos debruçados sobre documentos, sujeitos e coisas habitadas pela história, se ao final o que se apreende não é senão a ínfıma parte de uma experiência sempre fugidia e tangencial? 0 esforço só vale se, diante de mais essa limitação do mundo do arquivo, o historiador aprender a transformá-lo não em uma mina de informações múltiplas e de certo modo impossíveis de serem abarcadas, mas em um laboratório de prática da história. Um laboratório onde não se geram provas, mas possibilidades históricas (DAVIS, 1986, p. 10) do que pode ter sido sentido, experimentado e vivenciado no passado em torno de determinados fenômenos que, ao serem revisitados pelo historiador que se serve de determinado acervo, podem ser objeto de novas interpretações sobre o que já aconteceu.

Assim, as questões a serem formuladas em relação a fenômenos imutáveis do passado, como a profissionalização docente, levarão a compreender aspectos diferentes em torno da mesma experiência de ser professor, por exemplo. Mais do que decifrar um passado, trata-se de um esforço por compreender as inúmeras possibilidades vividas pelos sujeitos que nele estão envolvidos e sobre os quais nosso ofício, lembra Bloch, propõe-se a produzir conhecimento (BLOCH, 2001).

\section{O acervo sobre instrução pública do Arquivo paranaense}

Robert Darnton nomeia como algo inexprimível a sensação de saber sobre uma pessoa que viveu em outro tempo que não o nosso. Ele pontua a necessidade de interpretação sem cair no romantismo, baseando-se em fatos que advêm das fontes.

Diferentemente dos filósofos e literatos, nós, historiadores, devemos dispor de evidências para sustentar nossos argumentos, e não podemos simplesmente extraí-las de nossa cabeça. Nós as extraímos, sim, das caixas dos arquivos (DARNTON, 2000, p.240).

Pensando nas evidências, na procura dos "vestígios sensíveis da paisagem" (BLOCH, 2001, p.54), apresentamos o acervo do DEAPPR em três etapas: iniciaremos apontando e problematizando os instrumentos de pesquisa disponíveis; em seguida, procederemos à identificação dos fundos arquivísticos que contêm documentação referente à instrução pública no Paraná província; finalmente, descreveremos o conteúdo e os tipos de fontes que podem ser encontradas nos respectivos fundos documentais.

\section{Instrumentos de pesquisa}

Os instrumentos de pesquisa disponíveis para os historiadores que recorrem ao acervo do DEAP-PR relativo ao período provincial e dos quais temos lançado mão em nossas investidas no acervo, são basicamente quatro.

A pesquisa no sítio da instituição ${ }^{2}$ permite o conhecimento e a seleção prévia de parte dos dados do acervo, como: mensagens e relatórios de governo; relatórios de secretários de governo e boletins do arquivo municipal de Curitiba. Existe ainda, no mesmo sítio, o item pesquisa histórica/guia de fundos, que permite identificar os diversos fundos que integram o acervo, com uma descrição bastante genérica de seu conteúdo. Vale registrar que os relatórios acima mencionados já se encontram disponíveis, digitalizados, para consulta virtual.

Dentre os fundos documentais do DEAP-PR, o maior é aquele constituído pelas correspondências da secretaria de governo, denominadas APs (Arquivo Público). Essas encadernações foram organizadas por ano, podendo ter cada ano 35 livros e cada livro uma média de 200 a 300 páginas. A grande maioria

\footnotetext{
2 - Confira: <http://www.arquivopublico.pr.gov.br>
} 
dos APs possui ainda uma versão microfilmada. Nos APs é possível encontrar todo tipo de correspondência de governo do século XIX, tais como: documentos da repartição central de polícia, da instrução pública, da tesouraria da província, da secretaria dos portos etc.

Porém, apesar da grande variedade, esses documentos ainda não estão organizados por assunto, devendo o pesquisador folhear todos os APs em busca do seu tema/objeto. Dada a profusão dessa documentação, ela conta com um instrumento de pesquisa próprio, as pastas índices. Organizadas em fins da década de 1970, são divididas por anos, possuem breve descrição do conteúdo de cada um dos ofícios encadernados dentro de cada AP, destacando-se o nome do remetente, do destinatário, a data e a cidade do remetente. Sem dúvida, recorrer primeiramente às pastas é o melhor caminho para quem deseja empreender um pente fino no fundo das correspondências de governo.

Um terceiro instrumento de pesquisa, disponível apenas in loco, são os bancos de dados da instituição intranet, que são constantemente alimentados, existindo, inclusive, um específico para a instrução pública. Todavia, cabe alertar que se trata de instrumento produzido a partir das pastas índices, mas que não contém todas as referências à instrução pública que nelas são encontradas.

Por outro lado, esses instrumentos de pesquisa internos são indispensáveis para a localização dos demais fundos documentais da instituição. A busca pode ser feita por palavra-chave, nome do remetente/destinatário e localidade, contando, nesse último item, com a vantagem da atualização de nomes das regiões como, por exemplo, da antiga Freguesia do Iguaçu para o nome hodierno de Araucária ou da Vila do Príncipe para o da atual cidade da Lapa.

Um último instrumento de pesquisa, disponível na biblioteca da instituição, são os Boletins do Arquivo Público do Paraná, publicados com periodicidade variada desde fins da década de 1970. Embora sejam compostos, sobretudo, por compilações de documentos existentes nos diversos fundos do arquivo, oferecem importantes pistas para localização dos mesmos, uma vez que com frequência a instrução pública comparece entre os temas contemplados pelas várias edições dos Boletins. Além de trazer transcrições de documentos, indicam a localização do original no acervo da instituição.

\section{Os fundos documentais}

0 DEAP-PR é composto, no momento da escrita deste artigo, por 60 fundos $^{3}$. Nas pesquisas que temos realizado no acervo, concentramos nossos esforços em três deles: relatórios de governo, relatórios dos secretários de governo e secretaria de governo. Como se vê, há muito que se explorar nos demais fundos, mesmo para o século XIX. Se uma parte da pesquisa histórica também se faz pela intuição, como já salientaram, em diferentes momentos, historiadores como Bloch (2001), Ginzburg (1989) e Farge (2009), essa mesma intuição nos permite aventar - a partir das descrições e de tímidas incursões por outros fundos que documentos relativos à instrução pública podem estar misturados aos que compõem os outros 56 fundos.

0 conjunto relatórios de governo, disponível on-line, consta, para o período provincial, de 72 relatórios produzidos pelos presidentes e vice-presidentes da província, por ocasião da passagem de governo e das reuniões da assembleia legislativa provincial. No primeiro caso, trata-se de prestação de contas ao sucessor, enquanto no segundo, trata-se de prestação de constas à assembleia legislativa acompanhada do pedido para que os deputados provinciais lançassem sua atenção sobre determinados aspectos que o presidente julgava dignos de serem contemplados nos trabalhos dos legisladores.

3- Consideramos aqui os 58 fundos documentais listados no site mais os fundos relatórios de governo e relatórios dos secretários de governo, digitalizados e disponíveis no site da instituição. 
Quadro 1 - Assuntos discriminados nos relatórios de presidentes da província do Paraná

\begin{tabular}{|c|c|c|c|}
\hline 1850 & 1860 & 1870 & 1880 \\
\hline $\begin{array}{l}\text { Estado político da província e } \\
\text { tranquilidade pública }\end{array}$ & Tranquilidade pública & Tranquilidade pública & - \\
\hline Estado sanitário & Saúde pública (vacina) & Saúde pública (vacina) & Estado sanitário \\
\hline $\begin{array}{c}\text { Segurança individual e de } \\
\text { propriedade }\end{array}$ & Segurança Individual & $\begin{array}{c}\text { Segurança individual e de } \\
\text { propriedade }\end{array}$ & $\begin{array}{c}\text { Segurança individual e de } \\
\text { propriedade }\end{array}$ \\
\hline Administração da justiça & Administração da justiça civil & Administração da justiça & $\begin{array}{l}\text { Administração da justiça (ofícios da } \\
\text { justiça) }\end{array}$ \\
\hline Estado da capital & - & - & - \\
\hline Secretaria de governo & Secretaria de governo & Secretaria de governo & Secretaria de governo \\
\hline Repartições físicas & Repartições gerais* & - & - \\
\hline Força pública & Companhia de polícia (recrutamento): & Polícia - Companhia de Polícia & Polícia \\
\hline $\begin{array}{c}\text { Repartição especial de terras } \\
\text { públicas }\end{array}$ & Repartição especial de terras & $\begin{array}{l}\text { Repartição de Terras Públicas - } \\
\text { Medições de terras particulares }\end{array}$ & - \\
\hline Colonização & Colonização & Colonização & Colonização \\
\hline Catequese e civilização de índios & Catequese e civilização dos índios & - & Catequese dos índios \\
\hline Instrução pública & Instrução pública & Instrução Pública & Instrução pública \\
\hline Culto público & Culto público & Culto Público & - \\
\hline Agricultura & Agricultura e indústria & Revista Agrícola & - \\
\hline Estradas & Estradas & Estradas/Estradas de Ferro & Estradas/ estrada de ferro \\
\hline Obras públicas & Obras públicas & Obras públicas & Obras públicas \\
\hline Objetos diversos & Estabelecimentos pios (hospitais) & Casas de Caridade & - \\
\hline- & Eleições & Eleições & Reforma eleitoral \\
\hline- & Família imperial & - & - \\
\hline- & Divisão eclesiástica & - & - \\
\hline- & Divisão civil & - & - \\
\hline- & Divisão judiciária & Divisão Judiciária & - \\
\hline- & Administração da justiça criminal & - & - \\
\hline- & Estatística e estatística criminal & Estatística & - \\
\hline- & Guarda nacional & Guarda nacional & Guarda nacional \\
\hline- & Comércio & Casa de mercado & \\
\hline- & Navegação & Capitania do porto & Capitania dos portos \\
\hline- & Limites & $\begin{array}{c}\text { Limites entre o Paraná e Santa } \\
\text { Catarina }\end{array}$ & - \\
\hline- & Iluminação pública & Iluminação pública & - \\
\hline- & - & Guerra com o Paraguai & Assuntos militares \\
\hline- & - & Companhia progressista & - \\
\hline- & Tesouraria da Fazenda & Tesouraria da Fazenda provincial & Tesouro da Fazenda \\
\hline- & - & $\begin{array}{c}\text { Depósito de artigos bélicos } \\
\text { (enfermaria militar de Fortaleza da } \\
\text { Barra de Paranaguá) }\end{array}$ & (2 \\
\hline \multirow[t]{2}{*}{-} & - & Engenheiro da província & - \\
\hline & & Cadeias (presos e pobres) & - \\
\hline Correios & Correios & $\begin{array}{l}\text { Correio geral (telégrafo elétrico e } \\
\text { para sinais) }\end{array}$ & Correios \\
\hline- & - & Paço da assembleia & - \\
\hline- & - & - & Exposição \\
\hline- & - & - & Caixa econômica \\
\hline
\end{tabular}

Fonte: Relatórios do acervo do DEAP-PR (1854-1889)

* Incluem-se: Secretaria da polícia; Repartição especial de terras; Inspetoria geral de mediações; Correio; Secretaria do assistente; Capitania do porto e diretoria geral dos índios. 
Para situar o leitor do conteúdo desses relatórios, sem ficar descrevendo-os, o que tornaria este texto um tanto extenso, optou-se aqui pela organização de um quadro, com distinção entre décadas.

Como é de se esperar em uma dinâmica de governo, na qual podem e provavelmente surgem questões novas a cada gestão, a estrutura do relatório também mudava, de acordo com os problemas e assuntos que circulavam na província. Entretanto, identificamos que existia uma permanência na composição do relatório, não somente no que se referia à administração da província, mas também às questões policiais, comerciais, repartições de terras, comunicações (correios) e educação. Outros títulos aparecem, eventualmente, de acordo com fatos que determinada gestão vivenciou, como o caso da Guerra do Paraguai, das exposições e do item Caixa econômica.
0 fundo relatórios de secretários de governo, também disponível on-line, consiste em relatórios produzidos pelos diversos responsáveis pelas secretarias, sendo que, na maior parte, dizem respeito ao período republicano. Não obstante, existem ali importantes relatórios da Inspetoria geral da instrução pública da província do Paraná, como os referentes aos anos de 1859, 1871 e 1882. Esses relatórios geralmente eram enviados ao término de cada ano ou solicitados pelo presidente da província por ocasião da transmissão do cargo.

Os relatórios citados são, respectivamente, de Joaquim Ignácio Silveira da Motta, Bento Fernandes de Barros e Moysés Marcondes de Oliveira e Sá. Em uma primeira tentativa de descrever o conteúdo dos mesmos, elegeu-se a própria delimitação por títulos, feita pelos inspetores gerais:

Quadro 2 - Títulos discriminados nos relatórios dos inspetores gerais de instrução pública da província do Paraná

\begin{tabular}{|c|c|c|}
\hline Relatório de 1859 & Relatório de 1871 & Relatório de 1882 \\
\hline $\begin{array}{l}\text { - Inspetoria geral de instru- } \\
\text { ção pública (inspetores de } \\
\text { distritos; subinspetorias de } \\
\text { escolas; conselho literário); } \\
\text { - Estado da instrução } \\
\text { pública; } \\
\text { - Instituição primária; } \\
\text { - Instituições secundárias; } \\
\text { - Ensino particular; } \\
\text { - Estatística; } \\
\text { - Orçamento. }\end{array}$ & $\begin{array}{l}\text { - Ensino primário; } \\
\text { - Fisionomia moral de nossas escolas. } 0 \text { ensino religioso. } \\
\text { Sua direção; } \\
\text { - Frequência das escolas. Resultado de seu ensino. Exames; } \\
\text { - Necessidade de restaurar os alunos mestres. } 0 \text { modelo } \\
\text { que oferecem os pupil-teachers da Inglaterra é preferencial } \\
\text { ao sistema francês do stage. Bases para uma restauração } \\
\text { que reúne as vantagens de criar auxiliares para o ensino } \\
\text { nas escolas primárias e um núcleo de disciplina para a Es- } \\
\text { cola normal; } \\
\text { - Inspeção do ensino; } \\
\text { - Ensino secundário; } \\
\text { - Secretaria. }\end{array}$ & $\begin{array}{l}\text { - Instrução primária (escolas subvencionadas, } \\
\text { particulares, corpo docente); } \\
\text { - Escola normal; } \\
\text { - Escolas noturnas; } \\
\text { - Ensino secundário (Instituto Paranaense, } \\
\text { aulas avulsas de instrução secundária, curso } \\
\text { mercantil de Paranaguá, estabelecimentos } \\
\text { particulares); } \\
\text { - Secretaria da instrução; } \\
\text { - Biblioteca; } \\
\text { - Orçamento; } \\
\text { - Conclusão; } \\
\text { - Movimento pessoal. }\end{array}$ \\
\hline
\end{tabular}

Fonte: Relatórios do acervo do DEAP-PR (1859/1871/1882).

Os relatórios dos inspetores gerais aqui discriminados são mais uma fonte que possibilita, por meio de vestígios, identificar e compreender algumas das discussões que os sujeitos envolvidos com o ensino na província paranaense - presidentes, inspetores, professores - apontavam como pertinentes, desde a organização da estrutura da instrução pública até a comparação com os modelos de ensino que circulavam, advindos de outros países, e a composição do orçamento.

No fundo secretaria de governo estão as correspondências de governo, encadernadas nos APs, e os livros pertencentes às diversas secretarias do governo provincial, denominados códices. Dentro do acervo sobre instrução, nos APs, é possível encontrar mapas escolares, ofícios de professores para inspetores de ensino e presidentes e desses para os professores; pedido de mobília e material para as escolas; recibos de materiais comprados para a instrução pública; relatórios de professores e inspetores de ensino; exames de professores; cartas e abaixo assinado de professores e pais; legislação educacional paranaense até correspondências entre os 
chefes de governo, abarcando a discussão sobre o ensino primário e secundário na província do Paraná, as quais permitem localizar indícios acerca do ensino em outras províncias.

Essas correspondências deixam entrever, sobretudo, como já indicou Hilsdorf no estudo de documentação similar no arquivo público de São Paulo, "o cotidiano, os faits divers reclamados pela história mais recente" (HILSDORF, 1999, p. 14) bem como pela própria história da educação.

Além dos APs, no mesmo fundo, existem os códices, livros avulsos que contêm documentos específicos sobre determinado assunto e que receberam essa nomenclatura. No caso da instrução, permitem a busca por leis, portarias e decretos, bem como a pesquisa de relatórios de presidentes, organização do corpo profissional da instrução, estatísticas escolares de determinados períodos e registros de professores, inspetores e presidentes sobre mobília, método, materiais escolares, licenças, mapas escolares e frequências.

Para saber qual o assunto de cada códice, o pesquisador deve procurar no índice, diretamente no banco de dados, na intranet do DEAPPR. Destacamos aqui, de antemão, os seguintes códices referentes à instrução pública, com o número entre parênteses: títulos de professores públicos (042); professores aposentados (90); atos da inspetoria da instrução (104); penalidades impostas a professores e contratos (103); estatística das escolas (108); termos de exame de professores (118); utensílios remetidos às escolas (119); empregados da Instrução Pública (606); registro de licenças de professores (949); e termos de juramento de professores (951).

\section{Possibilidades inscritas nas fontes}

Lançando mão das quatro possibilidades de enfrentamento do acervo sobre instrução, já esboçadas no item anterior, debruçaremo-nos agora sobre algumas fontes e suas possíveis problematizações.

\section{Mapas escolares}

Em sua maioria, os mapas escolares eram enviados pelos professores aos inspetores ou por esses ao inspetor geral ou presidente da província, junto com os termos de visita daquela escola, trimestralmente. Ao longo do século XIX, sofreram modificações em sua estrutura.

Basicamente, os dados eram assim dispostos: número do aluno, nome, idade, filiação, data da matrícula (dia/mês/ano), o que sabe e observação. Nesse item da observação, é possível aferir alguns dados a respeito da instrução ou do aluno, nas raras vezes em que um professor ou inspetor escreve. Aqui, abremse algumas sugestões de pesquisa, como o tipo de experiência que emerge desses mapas acerca da história da escola e da escolarização da infância na província do Paraná ou da trajetória da instrução dessas crianças, originando-se pelo fio do nome (LEVI, 2000).

Segundo Jacques Revel, essa escolha permite uma abordagem diferente:

[...] permite destacar, ao longo de um destino específico - o destino de um homem, de uma comunidade, de uma obra -, a complexa rede de relações, a multiplicidade dos espaços e dos tempos nos quais se inscreve (REVEL, 2000, p.17).

A partir de 1883, os mapas escolares ganham reforço dos mapas denominados população escolar, que eram enviados pelos superintendentes do ensino obrigatório. Continham colunas diferentes de preenchimento com informações sobre profissão e nome do chefe da família; nome dos meninos e meninas; escola em que estava matriculado e, caso não estivesse, qual a preferência ou se ia receber o ensino em casa da família; distância aproximada da escola; rua ou cercania em que morava; relação de parentesco, subordinação ou dependência para com o chefe de família e observações.

Uma escolha para análise dos mapas escolares ou da população escolar poderia se 
ater às observações dos inspetores de ensino sobre o mapa do professor, anexado ao termo de visita da inspeção, permitindo, dessa forma, inferências a respeito da prática docente. Outra possibilidade é se servir deles para delinear o perfil das crianças e as diferentes infâncias que tiveram a partir do acesso à educação escolarizada naquele período.

\section{Ofícios de orçamento de material escolar}

Esse corpus documental, que cresce a partir da década de 1870 no acervo, permite diferentes problematizações: cabia a quem solicitar o material? Quem estava autorizado a conceber o recurso solicitado? 0 que estava listado e quem fornecia? Como interpretar essas requisições? São questões que, se respondidas, levarão à compreensão da cultura material escolar e suas distinções entre os séculos XIX e XX, no Paraná.

A troca de ofícios com pedido e orçamento de material e mobília escolar é uma constante durante a segunda metade do século XIX, encontrada, principalmente, nos livros APs. Cabia aos professores e inspetores de distrito/paroquiais enviar relatórios ao inspetor geral e presidente da província sobre o estado de suas aulas, desde a discriminação de quantos alunos estavam matriculados e frequentando, passando pelo método utilizado, condições da sala, número de alunos para exames até a identificação da composição material da mesma.

Podem-se encontrar três tipos de ofício envolvendo material escolar: listas do que havia na escola (feitas, geralmente pelo professor, ou pelo inspetor, quando esse realizava a visita); orçamento de materiais solicitados (feito pelo professor) e listas com solicitações diretas à inspetoria de instrução pública, ao presidente da província ou ao inspetor da tesouraria provincial (professor, inspetor de distrito/paroquial e inspetor geral).

Em muitos pedidos, o solicitante se remetia à legislação em vigor, especialmente aos artigos que delimitavam o material condizente a cada es- cola, para depois explicitar o que necessitava. Em ofício dirigido ao inspetor da tesouraria provincial, o inspetor geral enviou o orçamento das despesas com móveis da escola de Palmeira, pedindo:

1 tabuleta com as armas designando a Freguesia a que pertence e sua ordem;

1 cadeira de braços para o professor;

1 estrado com 12 palmos de largura e 1 metro de altura com 2 gavetas;

2 cadeiras de palhinha para os visitantes;

3 bancos de altura graduada para formar o anfiteatro;

2 mesas inclinadas para a $2^{\text {a }}$ e $3^{\text {a }}$ ordem, com alturas graduais e dimensões dos bancos com os competentes caixilhos envidraçados para traslados gráficos;

1 quadro preto;

2 cabides de paredes numerados;

1 campainha;

4 réguas (CODICE 101, 26/11/1857, p.08).

Com o tempo, é possível perceber o acréscimo de outros materiais, nos pedidos feitos pelos professores e inspetores, como, por exemplo, o relógio solicitado pelo professor Honório Décio, de Paranaguá (PARANÁ, AP 0137, 1862, p.157). Interessante possibilidade de análise é não somente perscrutar os objetos constantes nas diversas listas de inventários, mas cotejar com os objetos escolares demandados pelos professores, sugeridos/remetidos pelas autoridades e presenciáveis nos espaços escolares do ensino primário no século XIX.

\section{Relatórios de professores e de inspetores}

Existiam semelhanças e diferenças entre os relatórios, o que já promoveria uma discussão voltada para o modo/forma de escrita, para o formato de cada um e o assunto tratado. Nesses relatórios, algumas informações sobre o trabalho docente, método de ensino utilizado e alunos matriculados ficavam dispostas com maior evidência. Também neles evidenciava-se "o cotidiano escolar situado na teia de relações políticas, corporativistas, 
clientelistas, de intrigas" (BEZERRA, 2006, p. 4), em que seus autores estavam mergulhados, de forma semelhante à observada por Bezerra no arquivo público do Ceará.

Por meio dos relatórios, pode-se problematizar o mobiliário das escolas e as disposições das salas de aula, se arejadas, espaçosas, conservadas ou não, como fez o inspetor paroquial Zeferino Machado, de Vila de Tibagi, ao visitar a aula da professora Alcina Domitila:

a sala onde funciona a aula é espaçosa, decente e clara, fazendo sentir a falta de mobília por ser a que existe atualmente na aula emprestada sob responsabilidade da professora. (PARANÁ, AP 0662, 1882, p.19)

Não é uma lista de orçamento, mas os termos de visita dos inspetores também são importante fonte para compreender a composição da materialidade escolar paranaense.

\section{Cartas, recibos de mercadorias e abaixo-assinados}

Os poucos itens que conseguiram passar pelo crivo da seleção de quem guarda e do que guarda possibilitam uma informação a mais sobre a instrução. Cartas como a que o senhor Benigno envia para o inspetor paroquial, junto com uma quantia a ser doada para a instrução, com o objetivo de, segundo ele: "melhorar o estado material das escolas desta cidade, resolvi proporcionar-lhes todos os utensílios móveis necessários para mobiliá-la" (PARANÁ, AP 0624, 15/03/1881, p. 225), servem como exemplo de questionamentos possíveis, como: o que era considerado como necessário para uma escola, nesse período? Que relações esse homem tinha com a instrução? Alguma criança de sua família estudava nas escolas daquela localidade? Apesar do mesmo senhor completar que: "não tenho outro fim senão coadjuvar esta parte do serviço público que tem por fim a instrução"; por meio da procura da rede de relações, essa finalidade também poderia ser problematizada.
No que se refere aos abaixo-assinados, destaca-se que demarcavam a luta de pais, protetores e pessoas locais em favor de uma aula ou escola em sua cidade, seja para que essa continuasse a funcionar ou para que fosse aberta em local específico. Os abaixo-assinados também podiam ser a favor ou contra um professor, o que, contrapondo com as outras fontes encontradas para determinada cidade, oferecia indícios do que ocasionava tensões e elogios; de como o trabalho do professor era visto; que concepção de escola os subscritos tinham; bem como a percepção de que famílias se juntavam nessa petição e se havia o indício de sobrenome semelhante nos mapas escolares.

Enfım, as opções de pesquisa e problematizações são diversas e cabe aqui apenas uma visualização de uma pequena parte do seu potencial, com o escopo de deixar os futuros pesquisadores do referido acervo com expectativa de um porvir. Ponderando que a documentação gira em torno de 53.000 fontes primárias, a reorganização desse universo extrapola a capacidade administrativa, mesmo contando com os estagiários e voluntários do arquivo público. Somando o nosso tempo de pesquisa histórica nesse local, de pelo menos dez anos, o acervo referente à instrução pública permite muita discussão e questionamentos, principalmente do período provincial paranaense, ainda pouco explorado dentro das possibilidades apontadas.

\section{Considerações finais}

Diante do exposto, é inegável reconhecermos o lugar dos arquivos como espaços de potencialidades e questionamentos para o ofício do historiador, desse espaço que "impõe logo de início uma enorme contradição; ao mesmo tempo em que invade e imerge, ele conduz, por sua desmesura, à solidão" (FARGE, 2009, p. 20).

Uma espécie de isolamento do pesquisador, como "o indivíduo diante da multidão" (FARGE, 2009, p. 21) de pessoas, fragmentos, arranjos, objetos do universo educativo e suas relações 
com o campo social atravessam e desafiam nosso esforço e capacidade interpretativa em dar sentido a fios, fatos, histórias tão desconexas.

Entendemos que é nesse conflito que a tensão se organiza e, desse modo, instaura-se a exigência de operar entre a paixão de recolher os vestígios do arquivo, de oferecê-lo integralmente à leitura "e a razão que exige que ele seja habilmente questionado para adquirir sentido" (FARGE, 2009, p.21).

0 extenso e alargado conjunto documental que pudemos expor sobre o DEAP-PR, possível também em outros tantos arquivos, revela um emaranhado de possibilidades investigativas a respeito das experiências educativas empreendidas no Império, acerca dos proponentes envolvidos e destinatários do processo de escolarização, das finalidades e da materialidade que marcam e configuram o processo educativo.
Salientamos que a multiplicidade aqui evidenciada se dirige aos instrumentos, aos recursos, às fontes que o arquivo disponibiliza, como "um suporte que permita ao historiador buscar outras formas do saber que faltam ao conhecimento" (FARGE, 2009, p.58), assim como também no sentido do próprio exercício da crítica do arquivo e dos acervos como um dado lugar, referindo-nos àquilo que Certeau expressa no que se "permite e o que interdita" ver (CERTEAU, 1976, p. 27).

Desse modo, examinar, por exemplo, os fundos de pesquisa já mencionados anteriormente, os modos como estão constituídos, organizados e dispostos à consulta, pode nos ajudar a entender parte das escolhas que a eles foram dirigidos, ao mesmo tempo, evidenciar ferramentas empíricas pujantes a serviço do exame das possíveis histórias da educação a serem escritas. 


\section{Referências}

BEZERRA, José Arimatea Barros. Sistematização de fontes do fundo instrução pública do Ceará (1844-1889). In: CONGRESSO BRASILEIRO DE HISTÓRIA DA EDUCAÇÃ0, Anais. 4. Goiânia: SBHE, 2006.

BLOCH, Marc. Apologia da história ou o ofício do historiador. 1. ed. Rio de Janeiro: Zahar, 2001.

BRANDÃ0, Isabel Cristina de Jesus. Pesquisa em fontes primárias: algumas reflexões. Revista HISTEDBR On-line, Campinas, n. 28, p. 131-144, dez. 2007.

CARVALHO, Marta Maria Chagas de; NUNES, Clarice. Historiografia da educação e fontes. In: GONDRA, José Gonçalves. (Org.). Pesquisa em história da educação no Brasil. Rio de Janeiro: DP\&A, 2005, p. 17-62.

CATANI, Denice Bárbara; FARIA FILHO, Luciano Mendes de. Um lugar de produção e a produção de um lugar: a história e a historiografia divulgadas no GT história da educação da ANPED (1985-2000). Revista Brasileira de Educação, São Paulo, n. 19, p. 113-128, jan./abr. 2002.

CERTEAU, Michel de. A operação histórica. In: LE GOFF, Jaques; NORA, Pierre (Orgs.). História: novos problemas. Rio de Janeiro: Francisco Alves, 1976, p. 17-48.

CODICE 101. Silveira da Motta envia orçamento de móveis da escola de Palmeira. Curitiba, 26/11/1857, p. 08.

DARNTON, Robert. Entrevista. In: PALLARES-BURKE, Maria Lúcia. (Org.). As muitas faces da história: nove entrevistas. São Paulo: Editora da UNESP, 2000, p. 81-118.

DAVIS, Natalie Zemon. 0 retorno de Martin Guerre. Rio de Janeiro: Paz e Terra, 1986.

. Entrevista. In: PALLARES-BURKE, Maria Lúcia. (Org.). As muitas faces da história: nove entrevistas. São Paulo: Editora da UNESP, 2000, p. 81-118.

DEAP-PR. História administrativa do Paraná. Curitiba: Imprensa Oficial, 2000.

DUBY, Georges. 0 prazer do historiador. In: NORA, Pierre (Org.). Ensaios de ego-história. Lisboa: Edições 70, 1989.

FARGE, Arlette. 0 sabor do arquivo. São Paulo: Edusp, 2009.

GEERTZ, Clifford. Uma descrição densa: por uma teoria interpretativa da cultura. In: A interpretação das culturas. Rio de Janeiro, LCT, 2008, p. 3-24.

GINZBURG, Carlo. Mitos, emblemas, sinais: morfologia e história. São Paulo: Cia. das Letras, 1989.

. Ekprhasis e Citação. In: . A micro-história e outros ensaios. Lisboa: Difel, 1991a, p. 215-232.

. 0 nome e 0 como: troca desigual e mercado historiográfico. In: A micro-história e outros ensaios. Lisboa: Difel, 1991b, p. 169-178.

. Micro-história: duas ou três coisas que sei a respeito. In: Paulo: Companhia das Letras, 2006a, p. 249-279. . 0 fio e os rastros: verdadeiro, falso e fictício. São . 0 queijo e os vermes. São Paulo: Companhia das Letras, 2006b.

GRENDI, Edoardo. Micro-análise e história social. In: ALMEIDA, Carla Maria Carvalho de; OLIVEIRA, Mônica Ribeiro de. (Orgs.). Exercícios de micro-história. Rio de Janeiro, FGV, 2009, p. 19-38.

HILSDORF, Maria Lúcia. A série ofícios diversos do arquivo do Estado de São Paulo como fonte para a história da educação brasileira. In: VIDAL, Diana Gonçalves; SOUZA, Maria Cecília Cortez Christiano de. (Orgs.). A memória e a sombra: a escola brasileira entre o Império e a República. Belo Horizonte: Autêntica, 1999, p. 13-20. 
Tempos de escola: fontes para a presença feminina na educação escolar: São Paulo: século XIX. In: GONDRA, José. (ORG.). Dos arquivos à escrita da história: a educação brasileira entre o Império e a República. Bragança Paulista, EDUSF, 2002, p. 133-145.

JULIA, Dominique. A cultura escolar como objeto histórico. Revista Brasileira de História da Educação. Campinas: Editora Autores Associados, n. 1, p. 9, jan./jun. 2001

LEVI, Giovanni. A herança imaterial. Rio de Janeiro: Civilização Brasileira 2000.

LOPES, Eliane Marta Teixeira. Origens da educação pública: a instrução na revolução burguesa do século XVIII. São Paulo: Loyola, 1981. 0 vívido do sujeito. In: MONARCHA, Carlos; NÓVOA, Antonio. (Orgs.). História da educação brasileira, formação do campo. ljuí: Unijuí, 2006, p. 115-144.

NUNES, Clarice. História da educação: espaço do desejo. Em Aberto, Brasília, n. 47, p. 37-46, jul./set. 1990.

Caminhos da historiografia da educação: algumas reflexões. In: ALVES, Cláudia et al. (Orgs.). História da educação: desafios teóricos e empíricos. Rio de Janeiro: Editora da UFF, 2009, p. 41-50.

PARANÁ. Departamento de Arquivo Público do Paraná. AP 0137. Orçamento pedido por Honório Décio. Curitiba, 1862, p. 157. Departamento de Arquivo Público do Paraná. AP 0624. Carta do senhor Benigno ao inspetor paroquial. Curitiba, 1881, p. 225. Departamento de Arquivo Público do Paraná. AP 0662. Termo de visita de Zeferino Machado. PR, 1882, p.19.

REVEL, Jacques. A herança imaterial: trajetória de um exorcista no Piemnte do século XVIII. RJ: Civilização Brasileira, 2000.

SIMÕES, Regina Helena; FRANCO, Sebastião Pimentel. Arquivos, fontes e historiografia capixaba: tecendo espaços/tempos de reflexão, produção, socialização e investigação histórica da educação no Espírito Santo. In: CONGRESSO BRASILEIRO DE HISTÓRIA DA EDUCAÇÃO. Anais 3. Curitiba: SBHE, 2004.

XAVIER, Libânia Nacif. Particularidades de um campo disciplinar em consolidação: balanço do I Congresso Brasileiro de História da Educação (RJ/2000). In: CONGRESSO BRASILEIRO DE HISTÓRIA DA EDUCAÇÃ̃O. Anais 1. Rio de Janeiro: SBHE, 2000.

Recebido em: 08.09.2012

Aprovado em: 24.04.2013

Gizele de Souza é professora doutora do Setor de Educação e do Programa de Pós-Graduação em Educação da UFPR e coordenadora do Núcleo de Estudos e Pesquisas em Infânçia e Educação Infantil (NEPIE).

Juarez José Tuchinski dos Anjos é doutorando na linha de pesquisa em História e Historiografia da Educação no Programa de Pós-Graduação em Educação da Universidade Federal do Paraná e pesquisador do Núcleo de Estudos e Pesquisas em Infância e Educação Infantil (NEPIE).

Etienne Baldez Louzada Barbosa é doutoranda na linha de pesquisa em História e Historiografia da Educação no Programa de Pós-Graduação em Educação da Universidade Federal do Paraná e pesquisadora do Núcleo de Estudos e Pesquisas em Infância e Educação Infantil (NEPIE). 